\title{
Compassion in rehabilitation nurses who provide direct patient care: principles to pragmatics
}

\author{
Letitia Burridge* $P h D, M P H, B N$ (Hons) \\ Research Fellow, The Hopkins Centre: Research for Rehabilitation and Resilience \\ Menzies Health Institute Queensland, Griffith University, Brisbane, QLD, Australia \\ Postal address: Division of Rehabilitation, Room 1SI.32.4, Level 1, Building 17, Princess Alexandra Hospital, \\ 199 Ipswich Road, Woolloongabba, QLD 4102, Australia
}

Email: I.burridge@griffith.edu.au

Michele Foster PhD, BSocWk (Hons)

The Hopkins Centre, Research for Rehabilitation and Resilience

Menzies Health Institute Queensland, Griffith University, Brisbane, QLD, Australia

${ }^{*}$ Corresponding author

Keywords Nursing, rehabilitation, compassion, street-level bureaucracy.

For referencing Burridge $L$ \& Foster M. Compassion in rehabilitation nurses who provide direct patient care: principles to pragmatics. JARNA 2019; 22(1):7-15.

DOI https://doi.org/10.33235/jarna.22.1.7-15

\begin{abstract}
Introduction Compassion is a core nursing value that is expected in health care, but it is unclear how rehabilitation nurses practise compassion in direct care where care demands usually compete for limited resources.
\end{abstract}

Aim This paper reports qualitative findings from a study on the dynamics of nursing compassion in rehabilitation settings where direct patient care is provided.

Method This qualitative study was conducted in a specialist rehabilitation unit in a tertiary hospital in south-east Queensland, Australia, between August and December 2017. A convenience sample of nurses from the spinal injuries unit or brain injury rehabilitation unit participated in audio-recorded focus group discussions guided by open-ended questions. The transcripts were analysed thematically.

Findings Twenty participants attended one of seven focus groups. The first theme explored the moralities of compassion in rehabilitation nursing, revealing that compassion was a discretionary aspect of daily practice governed by individual rules in a context dominated by tasks. The second theme explored the differential compassion in rehabilitation nursing, highlighting both the versatility of compassion and factors which enabled and depleted compassion.

Discussion Rehabilitation nurses managed potential conflicts between expectations and realities by making choices that sometimes prioritised tasks and rationed compassion. Some nurses engaged in the additional, complex and less visible work of intervening to compensate for an observed lack of compassion in a person-centred model of care.

Conclusion Although compassion is recognised as an individual nursing action, it is also an organisational ideal which suggests opportunities for organisational initiatives to strengthen and sustain compassion in rehabilitation nursing. 


\section{Introduction}

Compassion is considered fundamental to professional nursing practice. Among its many advantages, compassion improves clinical outcomes and patient satisfaction (C. Strauss et al., 2016), and it also strengthens the nurse-patient relationship (Sharp, McAllister, \& Broadbent, 2016; van der Cingel, 2014). This makes compassion particularly valuable in rehabilitation nursing, which regards the nurse-patient relationship as integral to the long process of supporting patients to achieve their outcomes (Tyrrell \& Pryor, 2016).

How to adequately define compassion continues to be a topic of ongoing discussion and literature reviews. Nonetheless, recognising suffering and acting to relieve it are two key recurring characteristics of the concept of compassion in health care (Perez-Bret, Altisent, \& Rocafort, 2016; C. Strauss et al., 2016), in nursing (Sharp et al., 2016; van der Cingel, 2014), and in rehabilitation (MacLeod \& McPherson, 2007; O'Reilly, Pryor, \& George, 2015). Compassion has been conceptualised as a deliberate and virtuous response to a person, to know them, discern their needs and relieve their suffering through relationship-based understanding and action (Sinclair et al., 2018). A multinational study (Papadopoulos et al., 2016) found that nurses expressed their compassion by giving time to patients, being there for them and getting to know them. This is consistent with a review which found that, to patients, compassion means a sense of togetherness with an approachable nurse who has time for them, understands their needs and suffering, and keeps them informed (Durkin, Gurbutt, \& Carson, 2018).

While compassion is an assumption and expectation of professional practice, nurses must also manage many organisational pressures. Consequently, compassion will be reliant on professional and organisational support to develop and sustain compassion in daily nursing practice (Beardsmore \& McSherry, 2017). Indeed, the importance of reciprocity of compassion between nursing colleagues and between the organisation and nurses is a prominent international debate (Dewar, Adamson, Smith, Surfleet, \& King, 2014; McCaffrey \& McConnell, 2015).

Concerns about the lack of compassion in hospital nurses who provide direct patient care accord with awareness that it is a complex problem that cannot be attributed to nursing alone, and requires organisational commitment (Francis, 2013). Recent evidence suggests the practice of compassion is influenced by psychological factors, structural factors and inter-professional collaboration (Ledoux, Forchuk, Higgins, \& Rudnick, 2018). Social structural elements that affect capacity for compassion are particularly important in demanding clinical settings (Roche, Pidd, \& Freeman, 2009). Failure to address such elements in system-wide compassion initiatives can have a detrimental effect (O'Driscoll, Allan, Liu, Corbett, \& Serrant, 2018). For example, a chronic shortage of skilled nurses could weaken nurses' capacity for compassion in a stressful workplace (Beardsmore $\&$ McSherry, 2017). Nursing care and the delivery of health care is also constantly changing in response to more complex and costly demands on the system (Theander et al., 2016). Critically, nurses now work within multiple constraints such as increasing workloads, performance targets, funding models and workforce instability (Clarke, 2004; Freshwater \& Cahill, 2010). It is unavoidable that nurses who provide direct patient care will likely make pragmatic decisions in daily practice as they negotiate their roles amidst constraints and top-down pressures (Hoyle, 2014). For example, if using a computer at the bedside is seen to impede the nurse-patient encounter, rehabilitation nurses might, in the moment, resist a policy directive to use computerised records at the bedside, and use handwritten workarounds instead, even though it could increase their workload (Burridge, Foster, Jones, Geraghty, \& Atresh, 2018).

Barriers to nurses' compassion are identifiable at organisational, team and individual levels. For example, nurses often work in a culture that values fast work, but this can erode time with patients and generate pressure that compromises compassion; it might also be compromised by lack of time to attend to emotional wellbeing within the team, or by individual nurses' limited emotional capacity to manage demanding or aggressive patients and relatives (Christiansen, O'Brien, Kirton, Zubairu, \& Bray, 2015). Other barriers include basic human fears and defences that are activated when dealing with ongoing exposure to pain and distress, or fatigue due to the investment of emotional labour (Mannion, 2014).

Compassion is an important but under-researched issue in rehabilitation nursing for patients with acquired disabilities such as spinal cord injury (SCl) or brain injury (BI). One study (O'Reilly et al., 2015) produced evidence of compassion in rehabilitation following $\mathrm{BI}$ though was unable to explicate how paid carers manage common barriers to compassion including lack of time, and organisational demands and priorities at the point of direct care. Notably, the distinctive nature of rehabilitation nursing compared to other fields of nursing elevates compassion as a critical practice issue. Unlike acute nursing, rehabilitation nursing is characterised by relationship-based, hands-off support over a 
long rehabilitation trajectory where the goal is to restore patients' self-care (Pryor, Walker, O'Connell, \& Worrall-Carter, 2009). Furthermore, rehabilitation nursing can be intensified by complex neuropsychiatric issues including cognitive deficits, mood and anxiety disorders, psychosis and apathy (Rao \& Lyketsos, 2000), which require skilful, consistent and sustained therapeutic interventions (Mortimer \& Berg, 2017). At the same time, nurses face increasing patient acuity, staff shortages (Beardsmore \& McSherry, 2017) and under-recognition of their professional status (Bivins, Tierney, \& Seers, 2017). In these situations, nurses may feel pressured to make pragmatic decisions which do not necessarily align with professional or organisational expectations.

The incongruity between organisational objectives and practice in settings where direct patient care is provided is well documented. Lipsky (1980) first introduced the concept of public servants, such as teachers and nurses, as streetlevel bureaucrats to recognise the regularity of their day-today contact with citizens in the delivery of welfare services and discretion in dealing with their concerns. A key premise of Lipsky's Street-Level Bureaucracy theory (2010) (SLB) was that, despite the best intentions of street-level workers in their dayto-day dealings with citizens, these were often difficult to carry out because of policy constraints, organisational pressures and growing demand on services. As such, workers would typically have to make tough decisions in their daily interactions about how they allocated their time and dispensed any benefits and resources to citizens (Lipsky, 1980). Further, it was deemed essential for street-level workers to develop localised routines and practices to manage the challenges of citizen demands that often exceeded resources (Lipsky, 2010). These discretionary practices, recognised as choices made within known constraints (Durose, 2011), can relate to rules, values or work tasks which address the ability to perform certain routine roles and activities on a daily basis (Taylor \& Kelly, 2006). The issue of discretion is particularly relevant to nurses who provide direct patient care, as they are increasingly conflicted by the disparities between patient expectations and lack of health service resources, yet their values and tasks are critical to quality patient care (Bolton, 2004). Furthermore, SLB provides a critical lens to consider how compassion is applied in rehabilitation nursing practice, given the complex nature of tasks and likelihood of external constraints of a hospital setting.

This paper presents qualitative findings from a mixed-methods study on the dynamics of compassion in settings where direct patient care is provided. The aim of the parent study was to explore compassion through the perceptions and experiences of rehabilitation nurses who provide direct care for people with $\mathrm{SCl}$ or BI. The quantitative component of the study surveyed a sample of nurses working in $\mathrm{SCl}$ or $\mathrm{BI}$ rehabilitation, to measure their levels of compassion satisfaction, compassion fatigue and burnout, and their overall well-being. Respondents who attended a compassion literacy workshop were re-surveyed four weeks after the workshop. The quantitative results are not reported here.

\section{Method}

A qualitative design incorporating a focus group method was used. Institutional ethical approval was obtained, and all participants gave informed voluntary consent in writing.

\section{Participants and setting}

The pool of potential study participants comprised 103 full-time or part-time nurses and included long-term contract nurses with at least six months' continuous practice in $\mathrm{BI}$ or $\mathrm{BCl}$ nursing in specialist rehabilitation units in a tertiary hospital in south-east Queensland, Australia.

Nurses were eligible to attend a focus group if they had attended a compassion literacy workshop and had completed the preand post-workshop surveys on professional quality of life and personal well-being. A total of 39 nurses met these eligibility criteria.

\section{The compassion literacy workshop}

A 45-minute practice-oriented, interactive, small-group workshop introduced the concept of compassion literacy as a core competency for rehabilitation nurses. Compassion literacy synthesises the concepts of compassion and literacy, and indicates a key element of nursing practice whereby nurses cultivate the capacity for compassion and proactively show compassion (Burridge, Winch, Kay, \& Henderson, 2017). Participants explored their understanding of the meaning of compassion literacy and related terminology in the health care context, including underlying assumptions and challenges. Workplace and personal strategies for building compassion literacy were presented, and participants were invited to try one of these strategies in their practice context, such as a Clinical Compassion Café (Winch S et al., 2014) or time-out moments to acknowledge and respect self-limits. At the end of the workshop, participants received a self-directed learning (SDL) package that involved reading, critical reflection and practical activities related to building their compassion literacy. The workshop and SDL 
activities comprised 1.5 contact hours of continuing professional development.

\section{Focus group recruitment}

A member of the team (LB) provided a verbal and written explanation of the study to eligible nurses, and invited them to participate. The recruitment process was monitored to ensure diversity of opinion based on age, gender and professional experience.

\section{Data collection}

Focus groups of approximately one hour were conducted by a member of the research team, also an experienced group facilitator (LB). A discussion guide was developed from the literature to explore perceptions and attitudes regarding compassion, factors affecting the enactment of compassion, and strategies used to encourage compassion in practice. The discussions were audio-recorded for transcription and analysis. Standard demographic information was collected to describe the participants.

\section{Data analysis}

Focus group transcripts were analysed for themes (Braun \& Clarke, 2006). In the analytical process, two members of the research team (LB, MF) first read and applied open coding to transcript data with reference to the discussion guide topics. Open coding refers to the initial work of noting concepts that categorise words or sentences in the text being analysed ( $A$. Strauss \& Corbin, 1990). These codes were discussed and refined to produce a final coding framework with descriptors. The framework was applied to all transcripts to identify patterns and contrasts that provide insights into the study topic, and exemplar quotes were noted. Disparities were resolved through discussion.

\section{Ethics}

Ethical approvals for this research were obtained from Griffith University Human Research Ethics Committee (2016/905), and Metro South Health Human Research Ethics Committee (HREC/16/OPAH/594).

\section{Findings}

Participants $(n=20)$ attended one of seven focus groups. The first three groups were conducted between August and September 2017, while the remaining four were conducted in December 2017. The participants' demographic information is portrayed in Table 1. Almost half $(n=9,45 \%)$ held a Bachelor of
Table 1: Participant demographics $(\mathrm{n}=20)$

\begin{tabular}{|l|cc|}
\hline \multicolumn{1}{|c|}{ Characteristic } & N & $\%$ \\
\hline Female & 16 & $(80 \%)$ \\
\hline Mean age: 42 years (range: 26-59 years) & & \\
\hline Practice setting: & & $(75 \%)$ \\
\hline Spinal injury unit & 15 & $(5 \%)$ \\
\hline Brain injury rehabilitation unit & 5 & $(60 \%)$ \\
\hline Main position: & & $(35 \%)$ \\
\hline Registered nurse & 12 & $(5 \%)$ \\
\hline Enrolled nurse & 7 & $(5 \%)$ \\
\hline Assistant nurse & 1 & $(25 \%)$ \\
\hline $\begin{array}{l}\text { Mean time in current position: } 9.2 \text { years } \\
\text { (range 1.5-35 years) }\end{array}$ & & \\
\hline$<1$ year & 1 & $(5 \%)$ \\
\hline $1-10$ years & & \\
\hline$>10$ years & & \\
\hline a missing & & \\
\hline
\end{tabular}

Nursing degree, and half of the registered nurses $(n=6)$ were in senior clinical positions.

The two major themes are now presented. Theme 1 is: The moralities of compassion in rehabilitation nursing; and Theme 2 is: Differential compassion in rehabilitation nursing. Square brackets within extracts indicate minor editing for clarification, and non-italics indicate emphasis. Brief extracts within the text use double quotation marks.

Theme 1: The moralities of compassion in rehabilitation nursing

The first theme about the moralities of compassion is indicative of how nurses who provide direct patient care conceptualised compassion as both a moral and amoral value of professional practice. This contradiction was connected to the challenges of carrying out organisational expectations. On the one hand, compassion was the difference between simply carrying out the task as opposed to attending to patients with care. For one participant, this resonated with personal values:

It's not just to tick the box, but like how would you feel if you were treated like that. You want to treat them like you want to be treated (P13).

For other participants, it resembled empathy, as compassion was integral to how any sick or well person would like to be treated, including family and practising health professionals. 
[Putting] myself in the person's shoes, or think[ing] of them as a family member, like if that was my mum, how would I react; or my dad, my brother, my sister (P4).

Empathy, [being] insightful, caring, considerate, treating people with dignity and respect and all those values that we like to be treated with as health workers (P9).

However, the presence of compassion was not necessarily seen as normative, nor was its absence necessarily seen as problematic. Compassion was regarded as a personal value that could be expressed professionally, depending on the situation. In that sense, it was not taken-for-granted and nurses operated according to personal rules:

I personally think that it all comes down to personality, and people are different. Just because someone has chosen to be a nurse doesn't mean that they carry compassion for every situation ... You might have it for some, and not others, depending on the situation or personality ... some people have a greater capacity for it (P12).

Other participants found the absence of compassion incongruent with being a nurse. By implication, it was an obligation for those to learn as part of professional development:

I think it should be in our DNA; that's what we do; we're nurses; we care (P9).

That's good and fine, but I don't think everyone does. Not everyone is maternal, not everyone has those maternal instincts. Sometimes they need to be taught (P10).

There was evidence that some coped with this incongruity by compensating for colleagues who chose to focus on tasks over compassion. This typically took the form of doing more for patients, which could lead to resentment:

[Y]ou're taking on way more work than you need to be taking on because you don't want to have to let that patient be looked after by the one that's not compassionate. Because they are, they're just going through the motions, just doing their tasks, and so you're taking on more, and then you become fed up (P18).

It was clear that there were challenges in complying with an expectation of compassion in routine practice and, in some cases, it was an optional extra. Whereas one participant, remarked: "it's fair that it's an expectation" (P15), another talked about the demanding workload that made it difficult for nurses who provide direct patient care to "allow for those extra little frills" (P9). Individual nurses had to make choices in the moment whether to show compassion, knowing it could mean a trade-off between quality and efficiency:

We have to fight for our own patients because of equipment and time and space and stuff like that, so you know, where we've been forced to pick who gets the most compassion every day I guess in a way (P17).

I find myself often in a position where I suspect it looks like I'm not as efficient in my job, because instead of doing all my tasks quickly and efficiently, l'm stopping to talk to my patients to make them feel better. [It's] tricky, but how do you explain that to someone? It's very tricky to explain to someone who doesn't have that [sense of compassion] (P17).

In summary, Theme 1 suggests that, although compassion was a professional and organisational ideal, it did not translate automatically or consistently into the practicalities of direct care, where nurses made constant micro-decisions about compassion. It was legitimate to prioritise tasks over compassion when managing a heavy workload, and colleagues' indifference was often seen as an unchangeable personal characteristic. Compassion was a discretionary aspect of daily practice based on individual rules. Further, it was present and absent in settings where nurses provide direct patient care in a kind of antinomy that was accepted rather than explained. What constitutes these differences in the values and rules relating to compassion is discussed further in Theme 2.

\section{Theme 2: Differential compassion in rehabilitation nursing}

Theme 2 reflects the complex interactions of multiple factors influencing compassion in nursing practice. For example, these included personal rules, duty of care, professional boundaries and situational issues that influenced what choices nurses could make about compassion in daily practice. Compassion was practised in ways that were governed by individual nurses' rules and, for some participants, the rule was about finding opportunities to express compassion that they considered was meaningful for individual patients. Consequently, compassion tended to be a response based on sensitivity to patients' preferences: 
Everyone's different ... we have patients who like hot showers, the other person likes cold showers; but we only have one temperature. We can give them the option to regulate the temperature, not just shower them (P13).

However, nurses could also be conflicted in their choices because of the dual purpose in their professional roles, that of respecting different preferences and a professional duty of care:

[Y]ou have some nurses that could be considered compassionate nurses for taking [patients] out on the veranda and letting them [smoke] and turning a blind eye. But then you could also be considered compassionate by not doing that because you're actually taking care of the patient and their health, but disregarding the patients' wants ... But it could be taken as "That nurse is a bitch and she doesn't let me do what I want, and I like this nurse because she's compassionate" (P16).

Consequently, there was the intersection with professional boundaries as nurses talked about the need to "have boundaries too with your compassion" (P11). This was also related to the longevity of patients' rehabilitation and the potential for patients to challenge nurses' compassion. Nurses at times had to walk a fine line between compassion and imposing limits:

[We] acknowledge what they're going through ... there's a big culture down there about not allowing patients to swear ... [but] I say to the patients, "I know you're getting frustrated, I know you're angry, I know that it's part of you dealing with your spinal injury. It's OK to swear." I tell them it's OK to swear; "but as soon as you swear at me, it's a no-go", that's off the table and I tell them from day one (P1O).

The longevity of the rehabilitation relationship provided the unique conditions that could enable or deplete compassion in day-to-day practice. For example, the complex nature of patients' needs could challenge nurses' resolve to practise their compassion ethic:

I'm only new to nursing really, l've only been doing it about two years, but I think in this environment with our challenging patients I personally often find that I have to remind myself, he's got a brain injury, it's not personal, he's not necessarily doing it on purpose. And that centres me a little bit ... if I'm starting to feel annoyed or frustrated (P15).
While the example above alludes to the experience of nurses as an important factor, the interprofessional relationship was also influential in nurses' choices to exercise compassion. Good working relationships and being appreciated among your colleagues were common elements that encouraged nurses' compassion. The general perception was that a happy team was not only more functional and productive, but also more compassionate, although the fluctuations in morale indicated these optimal conditions could be neither contrived nor controlled:

When the morale in the ward is high, we tend to be more compassionate and more efficient, but when the mood is low, then we're being less compassionate, more frustrated and actually get less done (P16).

Verbalising genuine mutual appreciation within the team was an important compassion-enabler that was not taken for granted:

[J]ust saying thank you for a good shift, thanks for a good day. Thank you for backing me, or for being there to listen (P4).

Participants also highlighted how the multidisciplinary nature of the rehabilitation setting could influence how they practised compassion. Compassion from non-nursing staff could be a motivator to choose compassion:

If you haven't got compassion being shown from your senior staff, medical staff, allied health staff, to the other team members, it's very hard to keep going ... because they don't share the philosophy that nursing staff are important and we might need a bit of compassion at times (P2).

At the same time, the multidisciplinary approach could be disruptive. Task conflicts involving workloads and the routinisation of disciplinary practices and therapy scheduling within the specialist rehabilitation setting was an example. For some, this conflict reduced patients' access to core rehabilitation nursing therapies:

[Therapy] schedules start at ten o'clock in the morning. [A nurse has] four patients that require bowel therapy, hygiene care, feeds would be good, um medications, and that's supposed to be all attended for the whole four patients before $10 \mathrm{am}$... And you've got all these schedule conflicts ... that's where your compassion fatigue and everything comes in ... because the people 
are just so busy trying to get the patients up and out to do their therapy, and missing the important aspects of the patient (P19).

The unbelievable workload that we have these days with digital and everything - I guess that could all have an impact on the compassion we show our patients ... And I guess, it's sad to say, but the workload you have for that day and how you plan your shift, you hope that nothing adverse comes up [as] that can definitely affect the amount of compassion you have for that day (P6).

In summary, Theme 2 highlighted more than the versatility of compassion that ebbed and flowed in practice settings where nurses provide direct patient care. Nurses occasionally set limits to manage the points of friction between compassion and duty of care in a challenging practice environment. This theme also highlights the compassion enablers and depleters that nurses encountered. Some were spontaneous and others predictable as structural inertia. Notably, individual nurses managed these tensions and rationalised the presence and absence of compassion according to personal values and rules.

\section{Discussion}

This study explored compassion in practice from the perspective of nurses in $\mathrm{BI}$ and $\mathrm{SCl}$ rehabilitation. Assuming an incongruence between professional and organisational expectations and practice realities in settings where nurses provide direct patient care, the specific aim was to uncover how nurses managed potential conflicts by making choices about compassion in patient care. The findings demonstrate the compassion discretions nurses exercise in practice and the personal and external factors that impinge on their choices. Moreover, the themes attest to the individuality of nurses' discretionary actions based on their own interpretations of professional values and tasks amid constraints within the setting. The findings highlight the imperative of creating favourable conditions for nurses to choose compassion despite the conflicts.

Participants struggled to agree on how to conceptualise compassion. The lack of clarity identified by Dewar et al. (2014) makes sense of the contradictory findings of Theme 1 and makes the presence or absence of compassion conceivable, from a practical point of view. As rehabilitation nurses worked under pressure in delivering direct care, they were also making constant decisions about which patient/s would receive the extra touches that were recognised as compassionate. With echoes of the street-level principle that demand will most often exceed resources in public service delivery (Lipsky, 2010), these choices resembled implicit rationing in day-to-day practice. Similarly, the realities of task prioritisation by nurses in acute hospitals due to resource constraints have been highlighted in previous studies (Jones, Hamilton, \& Murry, 2015). Implicit rationing raises two concerns: 1) What is being missed in patient care, and 2) Does this rationing place some patients at greater risk?

Compassion revealed its multidirectional nature in Theme 2 . Rather than seeing compassion as a phenomenon in settings where nurses provide direct patient care (Schantz, 2007), our findings concur with recent literature, which acknowledges compassion as the responsibility of all hospital staff at all levels of the organisation (Bivins et al., 2017; McMahon \& White, 2017). In the realities of practice, however, the compassion of colleagues in the efficiency-driven organisation (Byers, 2017; Som, 2009) was thin. Organisational compassion towards nurses was not a finding. However, recent research (Ledoux et al., 2018) has identified its important role in removing the structural barriers to compassion in settings where direct patient care is provided, rather than simply mandating its practice. Individualised expressions of compassion are thus but the visible tip of a collective responsibility.

How nurses managed lack of compassion, or threats to it, was also explored in Theme 2. As both enabling and depleting factors could be present, compassion was not guaranteed in settings where nurses provide direct patient care. However, it was readily activated when the nursing team functioned well and understood the value of being respected and appreciated by colleagues, as others have found (Baggett et al., 2016; Christiansen et al., 2015). Likewise, the genuine appreciation of patients and family members motivated nurses to reciprocate the compassion. Despite increasing an already pressured workload, nurses' willingness to intervene to support a patient experiencing lack of compassion is an important finding because it highlights their commitment to compassion as a gesture of person-centredness. It also depicts the complex and less visible work of being watchful, reflective and flexible enough to adjust the individual scheduling of work in order to respond spontaneously to new needs. This raises questions about whether health professionals can learn compassion. Although opinion remains divided (Geraghty, Lauva, \& Oliver, 2016), the answers must lie beyond and not just within individual nurses.

Our findings stem from a small sample in one hospital, but provide insights into how rehabilitation nurses who provide direct 
patient care understand and practise compassion, and how they managed its absence. We acknowledge that the findings may have differed with more male participants. Likewise, it is possible that cultural or ethnic factors could have influenced the findings. These factors were not explored specifically in the present study but may be investigated in future research. The key implications for practice are shared: management and clinical personnel must collaborate to ensure that compassion can be practised consistently in settings where direct patient care is provided, without isolating it as a nursing-only imperative.

\section{Conclusion}

Compassion is an organisational ideal that is unavoidably rationed for rehabilitation nurses who provide direct patient care, where demands often exceed resources. Nurses made discretionary decisions about how, when and towards whom their compassion was expressed, including how to respond to lack of compassion. Although genuine appreciation from colleagues, patients and their families can activate compassion, compassionate nurses' workload expanded to compensate for colleagues' lack of compassion. Organisational compassion towards nurses remains an under-developed opportunity. This study provides direction for future initiatives to strengthen and sustain compassion in rehabilitation nursing.

\section{Acknowledgements}

We thank the participants for their valuable contribution to this research.

\section{Competing interests}

The authors have no competing interests to declare.

\section{Source of funding}

This research was funded in-kind by The Hopkins Centre and the Division of Rehabilitation at Metro South Health Service, Queensland Health.

\section{References}

Baggett, M., Giambattista, L., Lobbestael, L., Pfeiffer, J., Madani, C., Modir, R., ... Davidson, J. (2016). Exploring the human emotion of feeling cared for in the workplace. Journal of Nursing Management, 24(6), 816-824. doi:https://doi.org/10.1111/jonm.12388

Beardsmore, E., \& McSherry, R. (2017). Healthcare workers' perceptions of organisational culture and the impact on the delivery of compassionate quality care. Journal of Research in Nursing, 22(12), 42-56. doi:10.1177/1744987116685594

Bivins, R., Tierney, S., \& Seers, K. (2017). Compassionate care: not easy, not free, not only nurses. BMJ Quality and Safety, 26, 1023-1026. doi:http://dx.doi.org/10.1136/bmjqs-2017-007005
Bolton, S. (2004). A simple matter of control? NHS hospital nurses and new management. Journal of Management Studies, 41(2), 317333. doi:https://doi.org/10.1111/j.1467-6486.2004.00434.x

Braun, V., \& Clarke, V. (2006). Using thematic analysis in psychology. Qualitative Research in Psychology, 3(2), 77-101.

Burridge, L., Foster, M., Jones, R., Geraghty, T., \& Atresh, S. (2018). Person-centred care in a digital hospital: observations and perspectives from a specialist rehabilitation setting. Australian Health Review, 42(5), 529-535. doi:https://doi.org/10.1071/ $\mathrm{AH} 17156$

Burridge, L., Winch, S., Kay, M., \& Henderson, A. (2017). Building compassion literacy: Enabling care in primary health care nursing. Collegian, 24(1), 85-91. doi:10.1016/j.colegn.2015.09.004

Byers, V. (2017). The challenges of leading change in health-care delivery from the front-line. Journal of Nursing Management, 25(6), 449-456. doi:https://doi.org/10.1111/jonm.12342

Christiansen, A., O'Brien, M., Kirton, J., Zubairu, K., \& Bray, L. (2015). Delivering compassionate care: the enablers and barriers. British Journal of Nursing, 24(16), 833-837. doi:http://dx.doi. org/10.12968/bjon.2015.24.16.833

Clarke, S. (2004). Failure to rescue: lessons from missed opportunities in care. Nursing Inquiry, 11(2), 67-71. doi:https://doi.org/10.1111/ j.1440-1800.2004.00210.x

Dewar, B., Adamson, E., Smith, S., Surfleet, J., \& King, L. (2014). Clarifying misconceptions about compassionate care. Journal of Advanced Nursing, 7O(8), 1738-1747. doi:10.1111/jan.12322

Durkin, M., Gurbutt, R., \& Carson, J. (2018). Qualities, teaching, and measurement of compassion in nursing: A systematic review. Nurse Education Today (Jan 31). Retrieved from https://doi.org/10.1016/j. nedt.2018.01.025

Durose, C. (2011). Revisiting Lipsky: Front-line work in UK local governance. Political Studies, 59(4), 978-995. doi:https://doi. org/10.1111/j.1467-9248.2011.00886.x

Francis, R. (2013). Report of the Mid Staffordshire NHS Foundation Trust public inquiry; executive summary. Retrieved from UK:

Freshwater, D., \& Cahill, J. (2010). Care and compromise: developing a conceptual framework for work-related stress. Journal of Research in Nursing, 15(2), 173-183. doi:10.1177/1744987109357820

Geraghty, S., Lauva, M., \& Oliver, K. (2016). Reconstructing compassion: should it be taught as part of the curriculum? British Journal of Nursing, 25(15), 836-839. doi:https://doi.org/10.12968/ bjon.2016.25.15.836

Hoyle, L. (2014). 'I mean, obviously you're using your discretion': Nurses Use of Discretion in Policy Implementation. Social Policy and Society, 13(2), 189-202. doi:10.1017/S1474746413000316

Jones, T., Hamilton, P., \& Murry, N. (2015). Unfinished nursing care, missed care, and implicitly rationed care: State of the science review. International Journal of Nursing Studies, 52(6), 1121-1137.

Ledoux, K., Forchuk, C., Higgins, C., \& Rudnick, A. (2018). The effect of organizational and personal variables on the ability to practice compassionately. Applied Nursing Research, 41, 15-20. doi:https://doi.org/10.1016/j.apnr.2018.03.001

Lipsky, M. (2010). Street-Level Bureaucracy, 30th Annual Edition: Dilemmas of the individual in public service. New York: Russell Sage Foundation.

MacLeod, R., \& McPherson, K. (2007). Care and compassion: Part of person-centred rehabilitation, inappropriate response or a forgotten art? Disability and Rehabilitation, 29(20-21), 1589-1595. doi:10.1080/09638280701618729

Mannion, R. (2014). Enabling compassionate healthcare: perils, prospects and perspectives. International Journal of Health Policy and Management, 2(3), 115-117. doi:10.15171/ijhpm.2014.34 
McCaffrey, G., \& McConnell, S. (2015). Compassion: a critical review of peer-reviewed nursing literature. Journal of Clinical Nursing, 24(19-20), 3006-3015.

McMahon, A., \& White, M. (2017). Compassion in practice: connected, contested, conflicted, conflated and complex. Journal of Research in Nursing, 22(1-2), 3-6. doi:10.1177/1744987117691170

Mortimer, D., \& Berg, W. (2017). Agitation in patients recovering from traumatic brain injury: nursing management. Journal of Neuroscience Nursing, 49(1), 25-30. doi:10.1097/JNN.0000000000000253

O'Driscoll, M., Allan, H., Liu, L., Corbett, K., \& Serrant, L. (2018). Compassion in practice - Evaluating the awareness, involvement and perceived impact of a national nursing and midwifery strategy amongst healthcare professionals in NHS Trusts in England. Journal of Clinical Nursing, 27(5/6), e1097-e1109.

O'Reilly, K., Pryor, J., \& George, S. (2015). An exploration of the postintensive rehabilitation care of young adults with severe acquired brain injury. JARNA, 18(1), 18-26. Retrieved from https://search. informit.com.au/documentSummary; $\mathrm{dn}=305342630423854$;res= IELHEA

Papadopoulos, I., Zorba, A., Koulouglioti, C., Ali, S., Aagard, M., Akman, O., ... González-Gil, T. (2016). International study on nurses' views and experiences of compassion. International Nursing Review, 63(3), 395-405. doi:https://doi.org/10.1111/inr.12298

Perez-Bret, E., Altisent, R., \& Rocafort, J. (2016). Definition of compassion in healthcare: a systematic literature review. International Journal of Palliative Nursing, 22(12), 599-606.

Pryor, J., Walker, A., O'Connell, B., \& Worrall-Carter, L. (2009). Opting in and opting out: a grounded theory of nursing's contribution to inpatient rehabilitation. Clinical Rehabilitation, 23(12), 1124-1135. doi:10.1177/0269215509343233

Rao, V., \& Lyketsos, C. (2000). Neuropsychiatric sequelae of traumatic brain injury. Psychosomatics, 41(2), 95-103. doi:https://doi. org/10.1176/appi.psy.41.2.95

Roche, A., Pidd, K., \& Freeman, T. (2009). Achieving professional practice change: From training to workforce development. Drug and Alcohol Review, 28(5), 550-557. doi:10.1111/j.1465-3362.2009.00111.x

Schantz, M. (2007). Compassion: a concept analysis. Nursing Forum, $42(2), 48-55$.
Sharp, S., McAllister, M., \& Broadbent, M. (2016). The vital blend of clinical competence and compassion: How patients experience person-centred care. Contemporary Nurse, 52(2-3), 300-312. doi:http://dx.doi.org/10.1080/10376178.2015.1020981

Sinclair, S., Hack, T., Raffin-Bouchal, S., McClement, S., Stajduhar, K., Singh, P., ... Chochinov, H. (2018). What are healthcare providers' understandings and experiences of compassion? The healthcare compassion model: a grounded theory study of healthcare providers in Canada. BMJ Open, 8(3), e019701.

Som, C. (2009). "Quantity" versus "quality" dilemma of health staff in NHS UK: Does clinical governance provide a solution? Clinical Governance: An International Journal, 14(4), 301-314. doi:https:// doi.org/10.1108/14777270911007827

Strauss, A., \& Corbin, J. (1990). Basics of qualitative research: grounded theory procedures and techniques. Newbury Park, CA: Sage.

Strauss, C., Lever Taylor, B., Gu, J., Kuyken, W., Baer, R., Jones, F., \& Cavanagh, K. (2016). What is compassion and how can we measure it? A review of definitions and measures. Clinical Psychology Review, 47, 15-27. doi:10.1016/j.cpr.2016.05.004

Taylor, I., \& Kelly, J. (2006). Professionals, discretion and public sector reform in the UK: re-visiting Lipsky. International Journal of Public Sector Management, 19(7), 629-642. doi:https://doi. org/10.1108/09513550610704662

Theander, K., Wilde-Larsson, B., Carlsson, M., Florin, J., Gardulf, A., Johansson, E., ... Nilsson, J. (2016). Adjusting to future demands in healthcare: curriculum changes and nursing students' self-reported professional competence. Nurse Education Today, 37, 178-183. doi:https://doi.org/10.1016/j.nedt.2015.11.012

Tyrrell, E., \& Pryor, J. (2016). Nurses as agents of change in the rehabilitation process. JARNA, 19(1), 13-20.

van der Cingel, M. (2014). Compassion: the missing link in quality of care. Nurse Education Today, 34(9), 1253-1257.

Winch, S., Henderson, A., Kay, M., Burridge, L., Livesay, G., \& Sinnott, M. (2014). Understanding Compassion Literacy in Nursing Through a Clinical Compassion Cafe. Journal of Continuing Education in Nursing, 45(11), 484-486. doi:10.3928/00220124-20141027-14

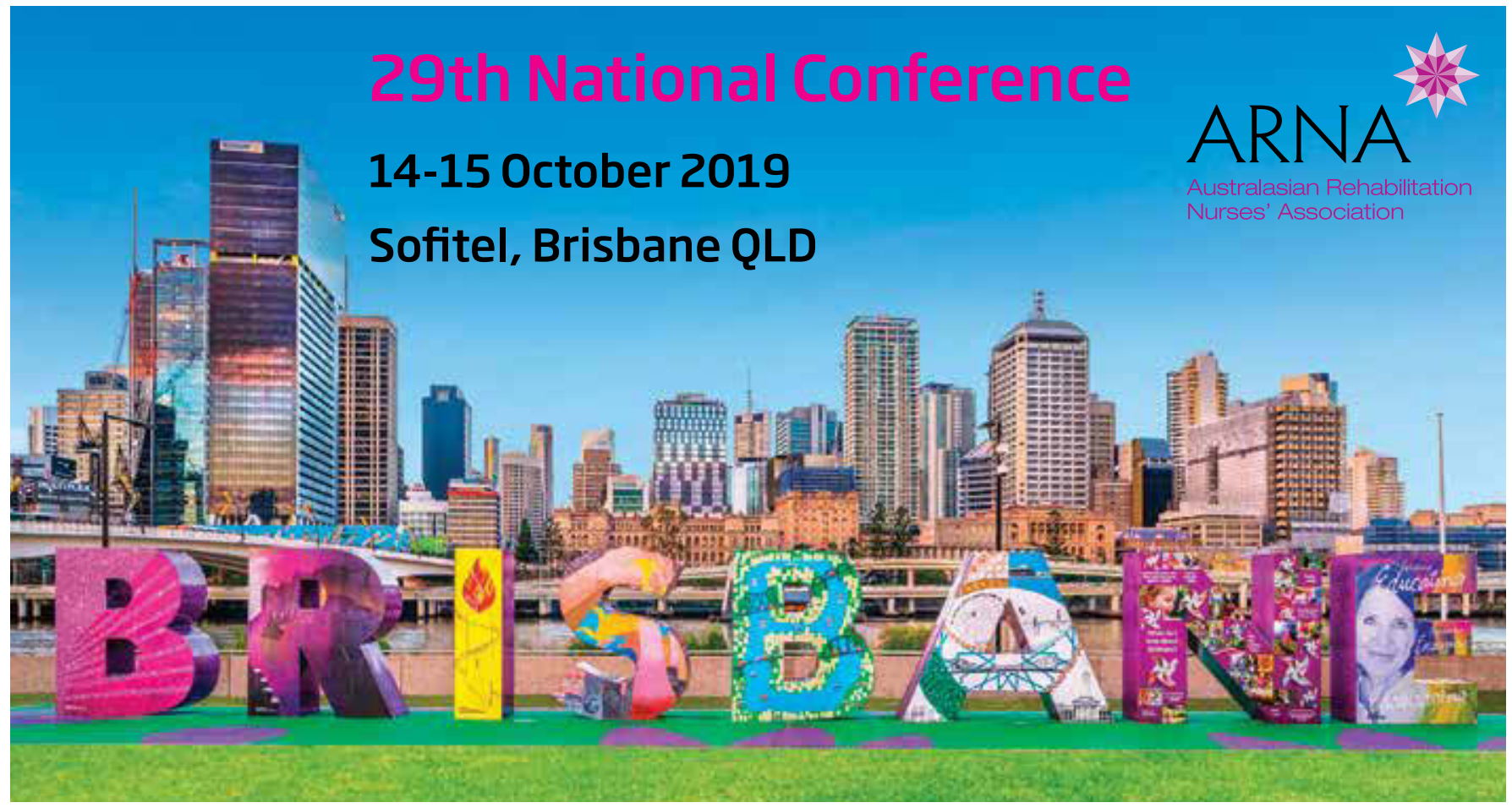

